\title{
O trote como sintoma: a dor de lidar com a dor alheia*
}

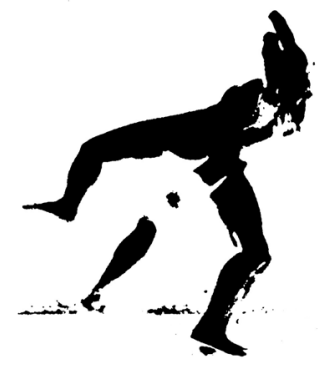

Renato Janine Ribeiro ${ }^{1}$

Não há desculpas para o assassinato, e o caráter fútil que ele assume no trote é particularmente imperdoável. Mas há outros aspectos a considerar. Não defendo o trote, porém lembro que ele é especialmente forte - $e$ chocante - em Escolas de Medicina, que lidam com experiências humanas radicais, como a morte, para a qual os estudantes nunca foram preparados. Ou seja: a mera proibição do trote, em suas modalidades violentas, embora mais que correta, não vai além da superfície de um problema crucial, que diz respeito ao modo como nossa sociedade pensa a sua relação com o insuportável, o horrível, e delega-a a pessoas que não têm ainda maturidade emocional, nem formação suficiente, para lidar com esses problemas. Pois depois de um ou mais anos de intensa dedicação aos estudos, quase sem se afastar dos livros ou do cursinho, jovens de vinte anos de idade se defrontam - nos cursos de Medicina - com a dor extrema, o sangue, a morte, o desespero de pacientes e parentes. São muito novos para saber lidar com isso, mas - sobretudo - não tiveram, nos cursos que fizeram, do ensino fundamental ao ensino médio, nem nos cursos que farão, na universidade, nem provavelmente em suas famílias, quase nenhum aprendizado sobre os aspectos psicológicos e humanos com que vão tratar.

\footnotetext{
* Algumas idéias deste artigo foram expressas, em versão bem mais curta, na Folha de São Paulo, em 7 de julho de 1999, sob o título "O trote e a dor".

${ }^{1}$ Filósofo, professor do departamento de Filosofia da Universidade de São Paulo.
} 
Nossa sociedade afastou a morte de seu convívio. Hoje, só por desventura se morre em casa. Para morrer, as pessoas são confinadas num ambiente neutro, hospitalar. Essa questão, aliás, foi analisada por vários historiadores, a começar por Philippe Ariès, que mostrou, no detalhe, como a morte foi sendo repelida do cotidiano, como deixou de fazer parte da vida, para ser algo que com ela entra em completa contradição e que, portanto, com ela não pode conviver. Um ponto de particular interesse para as profissões que lidam com a saúde foi a medicalização, melhor dizendo, a hospitalização da morte, que eliminou quase por completo a idéia de que se possa morrer em casa. As famílias minimamente abastadas praticamente sentem horror de ter, em sua residência, um aposento no qual alguém morreu. A morte, mesmo a não violenta, é, assim, deportada para um espaço asséptico curiosamente, o mesmo que seria o da recuperação da saúde, pois o hospital serve assim para todas as pontas em que a vida entra em contato com seus limites: o parto, a doença de que somos tratados e curados, a morte. Mudou também a idéia de "boa morte". Não são poucas as igrejas do período colonial dedicadas a ela. Séculos atrás, no auge da religião cristã, era boa a morte de quem a sentia vir, a tempo de se despedir da vida, do burburinho, dos entes queridos. Hoje, ao contrário, elogiamos a morte que chega sem avisar. É verdade que faz sofrer os familiares, que não tiveram tempo de se preparar para a perda, mas poupa o falecido, que não passou por anos de exames, de internações, de degradação. Evidentemente, quando a morte era passagem para um Além mais valorizado (pelo menos em tese) do que este "vale de lágrimas", o ideal seria que cada um tivesse o tempo de se arrepender do que fizera de mal, de fazer as pazes com as pessoas e os sentimentos. Por isso era bom ver a morte chegar: ela permitia o tempo da serenidade. Mas hoje, numa sociedade bastante laicizada, parecemos preferir a morte súbita. Não imaginamos suportar, como doentes, a lenta deterioração do corpo e da vontade, nem, como parentes, esforços e dispêndios cada vez maiores em troca de cada vez menos saúde. Em suma, nossa sociedade - priorizando o sucesso, a maximização dos ganhos - não sabe o que fazer da morte, da grande perda. E como pode então querer que jovens pouco experientes saibam lidar com ela? Note-se que não estou defendendo a restauração dos valores ditos morais, de uma religião talhada na medida para pôr ordem nos espaços que estão sendo trabalhados pela anomia ou a dúvida. Não pretendo defender a velha moralidade, até porque, primeiro, ela coonestava enorme hipocrisia, segundo, para se sustentar ela precisava de uma crença no absoluto e num outro-mundo feito de castigos e punições, ou, pelo menos, de recompensas: sua base era, assim, bastante interesseira. O que levanto como problema é outra coisa: estamos diante de um problema serí́ssimo, e como resolvê-lo? Restabelecer a velha moral, a antiga religião, é solucionar os efeitos sem mexer nas causas. A causa é essa experiência do horror que nada, repito, nada permite esconder (um termo técnico poderia ser "colmatar", obturar, tapar).

Ora, a "tecnologia" de que dispõem os acadêmicos de Medicina para lidar com a dor enorme é simples e velha: invertê-la, carnavalizá-la, brincar com ela. Aliás, o mesmo vale para os alunos de Direito, que também entram em 
2 Refiro-me ao livro de Júlio Cortázar, Histórias de cronópios e famas, no qual aparece esse tipo de pessoas, as "esperanças", que acreditam piamente no bem, na boa conduta, na produção de bons resultados mediante as boas maneiras e o bom comportamento. contato com o sofrimento alheio: num caso, a doença, no outro, a injustiça, fazem os jovens manter uma relação com os limites que nosso físico ou a organização de nossa sociedade, em suma, nossa natureza ou nossa cultura, colocam para o que seria bom, justo, adequado. A dor extrema presenciada assim nos põe diante da falência de tudo o que é ideal ou ilusão. É como se ela devastasse nosso lado "Poliana", nosso lado (diria Cortázar)

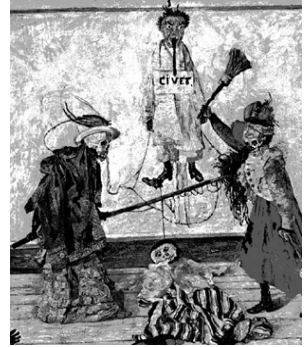
"pequena esperança" 2. Insisto: nada prepara ou preparou o jovem, ou dito de outro modo, já que todos nós somos ou fomos jovens, quase nada nos preparou para esse trato com o horrível. A falha está em todos nós. Por isso, na falta de maior sofisticação afetiva, lida-se com a dor extrema do outro mediante as técnicas default que foram sendo gestadas ao longo de milênios, e que visam a excluí-la, a construir em torno de nós uma espécie de cordão sanitário que a impeça de irromper em nossa psique, de infectar-nos, que portanto, assim, conjure seu lado contagioso (de propósito, utilizo imagens da linguagem médica, para mostrar como a dor é vivida como um mal. Ou seja: um fenômeno que surge na relação entre pessoas, de ordem portanto psíquica, sociológica ou antropológica, passa a ser tratado como um problema quase biológico, que requer - aparentemente - soluções não no plano dos sentimentos e de seu trato, mas no de ações práticas). A carnavalização foi muito estudada na Antropologia, e na história das mentalidades, estes últimos anos. Ela consiste numa troca de posições entre o sério e o burlesco, entre o trágico e o cômico. Assim, no carnaval, o pobre se torna nobre, o negro, aristocrata, o miserável, dançarino de primeira. $\mathrm{O}$ que está abaixo sobe. Pela mesma lógica, o que está acima pode descer - isto é, ser desqualificado num ritual de catarse. Assim, se vamos além de nosso carnaval brasileiro, criação esplêndida de nosso país e do século $\mathrm{XX}$, para $\mathrm{o}$ que foi o carnaval ao longo dos tempos, notamos a grande freqüência com que condutas são condenadas: geralmente, condutas de poderosos, em descompasso com um sentimento público. Por exemplo, na França do século $\mathrm{XVI}$, o charivari era o modo pelo qual os rapazes de pouco dinheiro zombavam de velhos que desposassem mocinhas. Estas eram objeto de desejo dos moços da mesma idade que elas, mas, como quem tinha dinheiro eram os mais velhos, acabavam sendo casadas com estes últimos; o sentimento, bastante difuso, de ser isso injusto, se exprimia mediante uma série de zombarias, dirigidas ao marido. Carnavalizar o existente era, assim, um modo de denunciar a injustiça, a desordem, o errado. Era um modo, numa sociedade em que a injustiça social era regra, de expô-la à execração $e$, não se podendo mudar a ordem das coisas, de pelo menos dar vazão à raiva, à insatisfação, à oposição a isso.

Há um ponto comum entre esses carnavais da tradição cultural pelo menos ocidental, $e$ as brincadeiras - de péssimo gosto - dos acadêmicos das profissões mais tradicionais, ou pelo menos dos de Medicina e Direito. Quando, por exemplo, se embebedam, ou procedem a trotes violentos, ou fingem pôr fogo em pessoas dormindo, tudo isso não nasce de um mero sadismo dos jovens. Conscientemente ou não (quase sempre, não), o jovem dá continuidade a uma longa tradição pela qual a única forma de lidar com o horror, com aquilo que ele mesmo no fundo tem dificuldade de aceitar, é 
mediante tais brincadeiras. Se, por exemplo, ele vai salvar vidas, mas no dia a dia tem que manifestar presença de espírito e mesmo frieza para cuidar de uma ferida ou proceder a uma operação, ele precisa excluir de si a dor enorme que lhe é transmitida, e o procedimento tradicional para tanto é o de brincar com isso. Até aí, que ele brinque, que faça piadas, não é em si nada mau. Não é diferente do que fazemos em nossos momentos de descontração, em que por exemplo falamos mal do chefe a quem admiramos, ou da companheira a quem amamos, para poder reequilibrar um descompasso que veio de algum excesso de trabalho, de alguma briga perfeitamente administrável. No caso em pauta, variações em torno do humor negro, do macabro, servem para exorcizar a dor extrema que, evidentemente, afeta o jovem que a vê $e$ de certa forma a compartilha.

Antes de prosseguir, vale a pena lembrar que a nossa sensibilidade "oficial" em face da dor alheia é relativamente nova. Quase podemos datá-la de Rousseau e de sua tese, sustentada no Discurso sobre as origens da desigualdade entre os homens (1754), segundo a qual o primeiro movimento de nosso coração, nosso primeiro sentimento, é a "piedade", que também poderíamos traduzir como "compaixão". Tratase do sentimento que nos faz sentir, com o outro, a dor que o afeta. Aliás, sentimos isso, diz Rousseau, em relação a qualquer ser vivo: não apenas seres humanos, mas também animais. Mesmo que não conheçamos o outro, a dor que o toca igualmente atinge a nós.

Essa idéia é nova, em seu tempo. Norbert Elias, em seu O processo civilizador, sobretudo no vol. $\mathrm{I}^{3}$, relata o prazer que tinham as multidões, por exemplo no século XVI, assistindo a execuções ou a suplícios de modo geral. Assim, quando faltassem condenados para o grande espetáculo popular que era uma lenta e dolorosa morte no patíbulo ${ }^{4}$, sucedia de uma cidade comprar alguns presos de outra povoação que os tivesse em excesso, ou até mesmo de animais domésticos serem mortos no cadafalso. Assistir à dor alheia era fonte de prazer. O problema, penso, é que talvez não tenha deixado por inteiro de proporcionar esses níveis de gozo. Nietzsche, na Genealogia da moral, fala com bastante lucidez do prazer de infligir a dor ou de vê-la infligida (e lembro que Nietzsche não defende tal prática, apenas observa a sua enorme ocorrência - é verdade que em tempos idos, mas sua leitura pode aplicar-se a nossa época também). Mesmo as execuções só deixaram de ser feitas em público há relativamente pouco tempo, - na França, quando terminava a década de 1930. Até então, eram espetáculos populares.

Em nossos dias, assim, o que acontece é que não temos mais a duvidosa coragem de assumir que sintamos prazer ao ver a dor alheia. O espetáculo do sofrimento infligido continua existindo - basta ouvir os programas matutinos das rádios, em que supostamente se denunciam criminosos mas na verdade se tem prazer em ouvir a narração de sua crueldade ou de sua morte, ou olhar as estantes de fitas de vídeo nas locadoras: mesmo aquelas, como a Blockbuster, que pudicamente se recusam a locar sexo explícito, não sentem vergonha em destacar filmes de violência. Finalmente, no caso da

\footnotetext{
${ }^{3}$ Trad. bras. por Jorge Zahar Editor, Rio de Janeiro, 2.ed, 1994.

${ }^{4}$ Sobre a técnica que consistia em infligir o máximo de dor pelo máximo de tempo, adiando sempre a morte a fim de aumentar o caráter exemplar do sofrimento mostrado ao público, ver Vigiar e Punir, de Michel Foucault.
} 
televisão, não se pode comparar a grita constante contra programas em que se mostra sexo, e a complacência bem maior demonstrada em face da violência. Contudo, todo esse prazer se disfarça, geralmente sob capa moralista.

O que acontece, em suma, é que nossa sensibilidade oficial, assumida de público, é rousseauista - de solidariedade com os desvalidos - mas por baixo dela continua pulsando uma sensibilidade de prazer com a dor alheia, porém que hoje necessita, para se expressar, de boas justificativas. O homem do século XVI tinha prazer imediato ante a dor alheia sem necessidade de justificar-se. Hoje, contudo, depois de duzentos anos de direitos humanos, sabendo que existe a igualdade pelo menos de direito entre todos nós, geralmente se pede auxílio a alguma boa razão para se justificar o prazer que se sinta com a dor do outro.

No caso do trote, a situação é ambígua. Por um lado, aplica-se dor sem nenhuma razão justificável ou perdoável: fazer alguém sofrer porque é nosso júnior é um contra-senso, porque o novo, o menor deveria ser protegido, jamais humilhado, pelo veterano. De tal ponto de vista, o trote dá continuidade a essas duas antigas tradições, a da carnavalização e a da dor infligida por prazer, a primeira delas mais ou menos rebelde, a segunda bastante conformista. Há mais um fator, porém. Como é injustificável infligir dor se não for - todo médico o sabe - como meio econômico para mais adiante suprimir uma dor pior, ou seja, como a dor aplicada apenas por prazer é inadmissível, em especial na profissão que um dia jura por Hipócrates, o sadismo assim expresso culturalmente precisa localizar-se num período bastante específico da vida, ou pelo menos do ano, e codificar-se em rituais coletivos, mais ou menos anônimos, de acumpliciamento generalizado. Note-se que não estou acusando de sádicos, pessoalmente, os que aplicam trotes; podem muito bem sê-lo, mas o que me interessa não é sua psique ou caráter individual, e sim o sentido social de seu comportamento. O sadismo eventual, mas bem datado, previsto no calendário, promovido de público e com um certo tom de brincadeira, constitui assim um ritual de descarga coletiva, de esconjuramento do horror que todos presenciam.

Evidentemente, tais condutas se deparam com problemas mais e mais intensos. O primeiro é que afrontam uma consciência cada vez mais difundida da universalidade dos direitos, do respeito à pessoa humana etc. $\mathrm{O}$ segundo é a presença das mulheres no ambiente acadêmico. Os rituais de trote são muito machistas em sua origem e natureza. Valorizam um tipo de comportamento comum entre machos pouco elaborados, que dão vazão a todas as funções ditas "baixas" do corpo (por exemplo, arrotos, vômitos, gases) - e que o fazem justamente, eis sua razão, para poderem assumir o resto do tempo um padrão de comportamento "elevado", de registro educado, bem-pensante. O problema é que essa válvula de escape vai ficando difícil quando o macho se defronta com o sexo feminino: as mulheres, ao longo do segundo milênio da era cristã, foram - enquanto objeto de desejo $e$ destinatário de um discurso da conquista sexual - a principal razão para se conter tais atos machistas e se refinar a conduta masculina ${ }^{5}$. 
Finalmente - terceiro ponto -, a tecnologia da carnavalização repousa numa espécie de contradição, ou de compromisso. Ela inverte as posições habituais da sociedade, e assim denuncia a injustiça, a desigualdade, o erro. Desse viés, é rebelde e mesmo subversiva. Mas só o faz em ambientes localizados, em datas ou momentos precisos - e, fazendo-o, quase sempre funciona apenas como exutório para um descontentamento que assim se sublima, que assim consegue uma satisfação imaginária ou simbólica, mas não se converte em ação que modifique, efetivamente, o que causa de fato o descontentamento. Eis o problema de toda carnavalização e, no caso, do trote enquanto válvula de saída para a dor insuportável: ele nunca enfrenta o problema para valer. Precisa ser reposto, ser repetido, o tempo todo. E, como se aceita que o estudante de Medicina ou Direito pratique o trote, que viole mesmo a lei e a moral para descarregar a dor que nele foi sendo introjetada, mas tal conduta é inaceitável para o médico ou advogado uma vez formado, a conseqüência disso é apenas transferir para a profissão inteira um problema que deixou de ser resolvido ou, sequer, de ser pensado no momento devido. Explico-me.

O espetáculo da dor física ou mental, no caso do médico, e da injustiça social, no do advogado, é um dado de partida. Pode, o jovem veterano das faculdades de Medicina e Direito, desforrar-se nos calouros da dor que ele próprio sente, e que além do mais sente como uma espécie de traição às promessas que imaginou receber dos mais velhos (vai exercer a "sublime missão de cuidar dos doentes, dos aflitos, dos perseguidos..."). Mas, formado, ele não terá mais o direito de vingar-se nos mais novos, e no entanto continuará sentindo essa dor - porque a limitação do trote (por ser carnavalização) é que ele nunca resolve o problema na sua raiz, mas apenas encena sua suspensão em seus efeitos. Para voltar às imagens médicas, não passa de um anestésico. Com o passar do tempo, o máximo que se oferece ao profissional de Medicina ou Direito é acostumá-lo ao espetáculo do insuportável. Quatro, cinco anos infligindo trotes ou praticando brincadeiras idiotas provavelmente o deixarão mais ou menos blasé, ou insensível - na aparência - à dor e à injustiça com que se defrontou. Ele se tornará um conformista, integrado na ordem social que gera ou multiplica dor e injustiça, e levará a vida adiante. Mas, evidentemente, isso o corroerá por dentro. Seria bem interessante um trabalho de pesquisa que fizesse um follow-up dos profissionais dessas duas grandes e importantes áreas, verificando como o fato de não se trabalhar adequadamente a dor compartilhada acaba tendo efeitos pessoais e sociais bastante negativos.

Essa é a questão, que vai além das condenações retóricas que criticam o varejo do trote e esquecem o atacado, isto é, os problemas colocados - no caso da Medicina - quando se procede à socialização de um infinito de dor. Se queremos pôr fim ao trote, ou torná-lo civilizado, social, precisamos antes disso pensar nos modos como nossa sociedade terceiriza o cuidado com o insuportável. Pois, na verdade, o eixo do problema é que a sociedade evita lidar com certas experiências-limite do ser humano, e delega-as a especialistas, os quais, porém, ela não se preocupa em preparar adequadamente. Pior, o que ela lhes atribui, como papel, é tratar o ser 
${ }^{6}$ Ver seu livro $A$ condição humana. Rio de Janeiro: Salamandra; São Paulo: Edusp, 1981. humano estritamente como coisa; desse ponto de vista, aliás, tudo se oferece em termos de facilidades; até na pesquisa acadêmica e científica se prefere uma abordagem que considere o humano como bios, como vida (o grande exemplo disso é o projeto Genoma), mas que deixe de lado o fato de que este ser somos nós, de que não só somos dotados de consciência como, mais importante, o pesquisador ou o médico é da mesma espécie que o pesquisado ou o paciente. Enquanto outros objetos da ciência são, sempre, apenas objetos, nós, e apenas nós, somos tanto objeto quanto sujeito - e já bastaria isso para perturbar as certezas que a pesquisa assim adquira a nosso respeito.

Uma distinção grega, retrabalhada por Hannah Arendt ${ }^{6}$, é aqui oportuna: refiro-me à diferença entre fabricação e praxis. Trata-se de distinguir dois modos de ação do ser humano. Um destes consiste em fabricar objetos, $e$ chama-se, em grego, téchne, de que provém a palavra "técnica". A fabricação supõe completa passividade do objeto assim constituído. Porém, há outro modo de agir, que em grego chama-se praxis, palavra que utilizamos na linguagem culta num sentido próximo ao de prática, mas que designa especificamente a ação sobre aqueles que também agem. O verbo prattein significa agir sobre quem igualmente age. A praxis não é, pois, uma prática qualquer; não é fabricação; é a prática que incide sobre os humanos, que também agem e com isso constróem extensa e complexa trama de ações $e$ interações.

Ora, todo o problema com que lidamos é que o sistema em que vivemos, quer nos hospitais, quer na universidade e mais além, vê muito mais sentido em fabricar do que em agir. Transpondo isso para a nossa questão do trote, veremos que há maior disposição em lidar com o ser humano enquanto alvo de sucessivas intervenções clínicas e cirúrgicas, as mesmas grosso modo que incidiriam sobre qualquer outro ser vivo, do que em considerá-lo na complexidade de sua psique, na sua capacidade de agir e reagir. Sabe-se com que dificuldade certos direitos dos pacientes, como o de ter acesso a sua ficha médica, vão sendo conquistados. O problema crucial é praticamente um só: nas áreas profissionais vive-se muito melhor o monólogo que o diálogo, e é essa postura enviesada que perturba não só o doente, a quem se nega a interlocução, mas o próprio médico (ou o advogado), cujo provável desamparo ou mesmo desespero ante a dor alheia é até mesmo desprezado, como sinal de fraqueza, em vez de ser trabalhado, em busca de uma desejável humanização.

Mas isto impõe duas tarefas. A primeira consiste em romper a distância, ainda enorme, que separa nossa consciência ética - expressa numa sensibilidade rousseauista da compaixão e dos direitos humanos - de uma reação afetiva mais ou menos automática, mal elaborada porém extremamente comum, que se deleita com a dor alheia ou pelo menos a tolera. Insisto, porém, que esta tarefa não se cumpre apenas com exortações à boa vontade, ou pregações religiosas. É preciso ir fundo, e pensar quais são os fatores sociais e psicológicos que reforçam a aposta no sofrimento. Prédicas e campanhas são insuficientes, e mesmo bastante duvidosas, porque confortam as pessoas na idéia de que basta reintroduzir alguma educação moral para pôr termo aos excessos, por exemplo, do trote. Ora, o problema, 
como argumentei, não está no exagero ocasional, e sequer no trote enquanto tal, mas nele enquanto sintoma de processo muito mais amplo $e$ sério de desumanização como procedimento sistemático para lidar com o outro que sofre.

E - eis a segunda tarefa - não será hora, cem anos depois de Freud e de tanto o que fizeram as ciências humanas ao longo do século $\mathrm{XX}$, de pensar em formas mais humanas de lidar com o sofrimento compartilhado? De inventar novos modos de lidar com a dor que presenciamos, e da qual queremos nos desfazer? Isso não vale só para o médico, mas cabe também para o advogado, o promotor, o juiz e o policial: para todos aqueles a quem se delega o papel de mediar nossa relação com o que mais nos devasta: morte, crime, injustiça.

No caso dessas profissões, há que rever, não uma cultura do trote que é apenas a ponta do iceberg, mas a idéia de que só nos desumanizando podemos suportar os extremos do humano. Há algo errado nessa crença, mas ela é tenaz, até porque vem da mais remota antigüidade. Em outras sociedades, porém, essa crença vinha junto com uma construção do cimento social de que fazia intensa e explícita parte o contrário da compaixão, porque ao longo dos milênios sempre se exibiu como festa pública o suplício cruel, e mesmo a pena de morte. Já em nosso tempo, a regra é a terceirização, nome muito recente que estou usando para procedimento que pode, no que nos interessa, ser datado de trinta ou cinquenta anos pelo menos: as atividades mais dolorosas, as que mexem mais com a sensibilidade humana, são profissionalizadas e delegadas a pessoas que ficam distantes de nós. Isto significa que entre nós o horror é vivido mesmo como horror, como inaceitável, mas como, ao mesmo tempo, não se sabe lidar com ele, a única saída é excluí-lo, afastá-lo de nós, e tratar com ele de maneira pretensamente técnica, acreditando-se que mediante uma somatória de instrumentos (os inúmeros de que dispõe o médico, o código do advogado, a arma do policial) se pode dar conta de um problema que em sua essência não é técnico, mas social, humano. Sistematicamente, assim, a sociedade varre o seu horror para baixo do tapete.

Se queremos uma sociedade melhor, precisamos ir fundo. O dever da sociedade é deixar de ser hipócrita e de condenar apenas os indivíduos que foram pegos excedendo-se nos papéis que lhe foram delegados. Deixo claro que merecem punição, sim, e que o trote violento deve mesmo ser proibido, com seus praticantes sendo punidos no âmbito da universidade $e$ mesmo no da lei penal. Apenas, não cabe tratar, numa retórica fácil, o trote como mero excesso, que seria reprimido deixando-se incólume tudo o que há de insuficiente na formação e na administração do médico. Isto significa, também, um dever ou uma responsabilidade mais específica $e$ precisa dos Conselhos de Medicina, aos quais cabe lidar com a desumanização ou pelo menos com a perplexidade que afeta os médicos já formados, e das universidades, as quais devem mexer nos currículos para pensar menos o corpo humano como objeto de práticas apenas técnicas, $e$ mais a intervenção médica como parte de uma praxis na qual humanos agem sobre humanos.

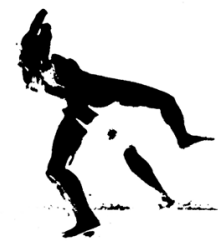

